\title{
Libertas, 20 anos! (Editorial)
}

Este novo número tem um significado especial para a Faculdade de Serviço Social e para o Programa de Pós-graduação em Serviço Social da UFJF: com ele, a Revista Libertas completa 20 anos desde a sua primeira publicação. Naquele momento estavam na direção da Faculdade de Serviço Social as professora Sandra Hallack Arbex e Édina Evelyn Casalli Meireles de Souza que, junto à primeira comissão editorial conformada pelas professoras Auta Iselina Sthephan Souza, Édina Meireles de Souza, Monica A Grossi Rodrigues e Begma Tavares Brabosa, se atreveram a sonhar e acreditar que seria possível construir uma revista da Faculdade que hoje é uma referência para o Serviço Social. E já completamos 20 anos... Lá pelo século passado, diziam os poetas Carlos Gardel e Alfredo Lepera que "20 anos não são nada", mas nestes tempos vertiginosos, em que somos cobrados pelo trabalho quantitativo muito mais que pelo qualitativo, em tempos da cultura do "efêmero e aleatório", resistir e, nessa resistência, persistir na qualidade, não apenas no que diz respeito a esta publicação, mas também em relação à formação oferecida pela Faculdade de Serviço Social da UFJF, seja na graduação ou na pós-graduação, em uma conjuntura nada favorável, é uma conquista realizada a muitas mãos. Não teríamos como mencionar cada professor, técnico, bolsista que dedicou parte de seu tempo de trabalho para a Revista. Também não teríamos como agradecer suficientemente aos pareceristas, que de modo voluntário, cuidadoso e extremamente sério avaliaram cada um dos artigos que enviamos. Fazer ciência no Brasil, não é tarefa simples. Não poderíamos deixar de mencionar os artistas que nos presentearam durantes anos com as fotos que deram a "cara" da nossa revista; a todos eles muito obrigado.

Há duas décadas, abríamos o primeiro número da Revista Libertas com um artigo ${ }^{1}$ da professora Rita Jacometti, no qual realizava uma reconstrução histórico-crítica do processo de constituição da Faculdade de Serviço Social - faculdade, hoje, sexagenária. Posteriormente, em 2005 sob direção das professoras Marilene Schelgshorn dos Santos Sansão e Auta Iselina

\footnotetext{
1 Todas as Revistas Libertas podem ser acessadas no nosso site: https://periodicos.ufjf.br/index.php/libertas $\underline{\text { issue/archive. }}$
} 
Sthephan Souza novos voos seriam alçados: seria criado o Programa de Pós-Graduação em Serviço Social, no nível de Mestrado, sob a coordenação das professoras Maria Aparecida Tardin Cassab e Maria Lúcia Duriguetto e, com sua consolidação, o Doutorado, em 2019. Dessa forma, também homenageamos o Programa de Pós-Graduação em Serviço Social, que após 15 anos continua demonstrando a sua qualidade, sendo ainda único Programa de Pós-Graduação em Serviço Social de Minas Gerais. Parabéns aos mestrandos e doutorandos, aos professores e técnicos administrativos que insistem em manter de pé a perspectiva crítica no Brasil. Portanto, apesar dos tempos sombrios que vivemos, no Brasil e no mundo, temos um legado para honrar e muita história para construir. Em 2002, a Revista Libertas era lançada em formato impresso; as mudanças produzidas no universo editorial, fizeram com que adotasse, em 2007, o formato online (a partir de 2016, a revista passou a adotar exclusivamente o formato online). Adaptarse ao "mundo online", ainda que sem dispor de estrutura e meios adequados, foi e continua sendo um desafio, não só pelas exigências (cada vez maiores) de indexação, controle de originalidade, fluxos editoriais, sistemas de edição etc. A Revista Libertas, a exemplo da maioria das revistas universitárias no Brasil, mantém a oferta de acesso gratuito e universal aos artigos científicos, traduções, entrevistas e outros materiais que publica; nada cobra de seus autores para publicar, ainda que enfrente dificuldades, muitas das quais, de ordem elementar, fruto das sucessivas políticas de restrição de orçamento para a produção e a publicização da ciência no Brasil. Não se enganem aqueles que pensam que a produção (e a publicização da produção) científica no nosso país se dá de forma suave; não. Antes, elas envolvem, na quase totalidade das vezes, o empenho pessoal dos pesquisadores e cientistas em sua realização, execução de tarefas para (muito) além do horário de trabalho, empenho de recursos financeiros próprios (pessoais), colaboração voluntária de um sem-número de docentes, técnicos e discentes, para que a ciência no Brasil continue caminhando, sob e contra os ataques daqueles que apostam sempre suas fichas na ignorância, na censura e na pax romana. Muitas revistas terminam por sucumbir nesse processo - como não lembrar o caso da Revista Estudos de Literatura Brasileira Contemporânea, editada pelo Grupo de Estudos em Literatura Brasileira Contemporânea da Universidade de Brasília desde 1999 e com 62 números publicados, qualificada em nível de excelência da CAPES (Qualis A1), que não teve as condições necessárias para manter a publicação, encerrando suas atividades em maio deste ano? Outras revistas terminaram por tomar outro caminho, na tentativa de remediar as dificuldades: transferir parte dos custos da publicação ao autor. Ainda que essa possa parecer uma saída racional no interior de uma sociedade onde tudo se dá pelo trânsito mercantil, restará sempre a dúvida, nesses casos: afinal, quem poderá publicar? Como se resolverá o dilema entre um artigo 
de elevada qualidade sem aporte de recursos financeiros e aquele mediano, com possibilidade de arcar com sua própria publicação? De um modo geral, cabe a pergunta para o futuro do sistema editorial: publicará mais quem pagar mais, ou publicará mais quem produzir melhor? Alterações no Qualis, que serão realizada em breve, também suscitarão dúvidas e debates.

Em meio a toda turbulência, a Revista Libertas mantém-se preocupada com a qualidade dos artigos que publica, a transparência nos processos de avaliação por pares e o acesso universal, público, gratuito. O compromisso da Libertas é com o saber científico, a perspectiva crítica, os movimentos sociais, as lutas sociais, a construção do projeto ético-político do Serviço Social. Os tempos mudaram e, com eles, novas exigências vão sendo colocadas; em meio a cortes orçamentários, falta de equipamento e estrutura, de pessoal especializado (tradução para outras línguas, revisores, técnicos para operar os sistemas de informação) etc., cada publicação é uma conquista.

De 1995 para cá, com maior ou menor ímpeto, a universidade pública brasileira vem sendo sistematicamente atacada e desmontada. Atualmente, acusada de ser espaço de balbúrdia, de práticas de orgias e de produção e uso de entorpecentes ${ }^{2}$, como num culto dionisíaco permanente. Espanta, mas não surpreende: é natural que a universidade, como espaço de manutenção de uma "atmosfera de saber para se preparar o homem que o serve e desenvolve", como a guardiã do "saber vivo e não morto", como difusora "da cultura humana", como "a casa onde se acolhe toda a nossa sede de saber e toda a nossa sede de melhorar" ${ }^{3}$ não pode ser tolerada pelo obscurantismo, pelos soldados da "decadência ideológica", por aqueles que preferem as sombras, onde todos os gatos são pardos, à luz do esclarecimento, onde as nuances e diferenças, muitas vezes sutis, mas decisivas, são perquiridas e explicitadas. Aos cortes no financiamento, continuamos respondendo com a reconhecida qualidade que a universidade pública possui. Como negar que, em meio às mais de 470 mil mortes por COVID-19, no Brasil, são justamente as universidades públicas, junto com os milhões de profissionais da saúde, que estão na linha de frente do enfrentamento da doença, com mais de $1.300^{5}$ pesquisas diretamente voltadas para o conhecimento e a superação da pandemia? Contra os fatos, opõem-se delírios

\footnotetext{
${ }^{2}$ Como esquecer das palavras do então Ministro da Educação, Abraham Weintraub, nos idos de 2019, de que "há 'plantações extensivas de maconha' nas universidades federais, 'a ponto de precisar de borrifador de agrotóxico'?" Disponível em https://educacao.uol.com.br/noticias/2019/11/22/weintraub-ha-plantacoes-extensivas-demaconha-em-universidades-federais.htm.

${ }^{3}$ Todos os fragmentos entre aspas são citações extraídas de TEIXEIRA, Anísio. A função das universidades. In TEIXEIRA, Anísio. Educação e universidade. Rio de Janeiro: Editora da UFRJ, 2010, p. 29-42.

${ }^{4}$ Cf. Marx e o problema da decadência ideológica. In LUKÁCS, G. Marx e Engels como historiadores da literatura. São Paulo: Boitempo, 2016, p. 99-156.

5 Os dados são do ano passado (2020) e podem ser encontrados em https://jc.ne10.uol.com.br/colunas/enem-eeducacao/2020/04/5607222-nas-universidades--cientistas-entram-na-luta-contra-o-coronavirus.html.
} 
persecutórios que, fazendo vista grossa para a realidade objetiva de que, em meio a pesquisadores, professores, alunos e técnicos administrativos aderentes aos mais variados espectros políticos, da esquerda à direita, passando pelo centro, de ateus a católicos, protestantes e umbandistas, de diferentes orientações sexuais, concepções de mundo etc., insistem em reduzir as universidades públicas ao imaginário desértico, pouco criativo e enfadonho de "antro da esquerda", de "berço e criadouro do marxismo cultural inspirado em Gramsci". E, justamente por isso, talvez seja oportuno falarmos em Gramsci.

É justamente a este importante pensador do século passado que dedicamos o nosso dossiê. Combatente empedernido do fascismo na Itália, oriundo de uma região rural, pobre, como muitos brasileiros, Gramsci estudou com dificuldades. De uma inteligência incomum, Gramsci uma herança teórico-política que, ainda hoje, desperta paixões, à esquerda e à direita. Sua permanência pode ser notada não apenas no debate popular - onde seu nome, agora, tornase cada vez mais lugar comum - mas, principalmente, pelos estudos sérios de seu legado: uma obra que teima em apontar caminhos e possibilidades para pensar, resistir e projetar um outro futuro.

No Serviço Social brasileiro a influência de Gramsci é inconteste. Sob o influxo do Movimento de Reconceituação Latino-americano, datado de 1965 a 1975, é que o Serviço Social se aproxima do pensamento marxista, mesmo que de forma enviesada 6 , mas será, sobretudo, a partir dos anos de 1980, que esta aproximação, amadurecerá e ganhará estatuto teórico. Como sinalizou Ivete Simionatto, desde final dos anos 70 o pensamento gramsciano terá grande influência no debate acadêmico e político:

Adensa os debates na apreensão das dimensões da política, da cultura e da ideologia, por meio de categorias como Estado, sociedade civil, sociedade política, hegemonia, intelectuais, filosofia da práxis, classes subalternas, revolução passiva entre outras. É a partir da recuperação desses referenciais que o Serviço Social se interroga sobre questões relativas às instâncias estrutural e superestrutural, com problematizações não somente respeito à esfera econômica, mas também política, ideológica e cultural. ${ }^{7}$

Simionatto destaca o Programa de Pós-graduação da PUC-RJ, sob a orientação da professora Miriam Limoeiro Cardoso, que teve um papel fundamental para o desenvolvimento

\footnotetext{
${ }^{6}$ Cf. NETTO, J. P. O Serviço Social e a Tradição marxista. Revista Serviço Social e Sociedade. São Paulo, Cortez n. ${ }^{\circ} 30,1988$.

${ }^{7}$ SIMIONATTO, I. (2018). As abordagens marxistas sobre os fundamentos no Serviço Social. In GUERRA, Y., LEWGOY, A. M. B., MOLJO, C., SILVA, J. F; SERPA, M. (Orgs.). Serviço Social e seus Fundamentos: Conhecimento e Crítica. Campinas: Papel Social, 2018, p. 90.
} 
teórico e político desta perspectiva de análise na profissão ${ }^{8}$. Do mesmo modo os trabalhos desenvolvidos pelo grupo da Faculdade de Serviço Social do Maranhão, conhecido como o "Grupo de Maranhão", nas figuras de Josefa Batista Lopes, Marina Maciel de Abreu, Franci Gomes Cardoso, entre outros, foram fundamentais para o adensamento desta perceptiva no Serviço Social brasileiro.

Nesta direção, também é inconteste a contribuição pioneira do professor Carlos Nelson Coutinho, uns dos maiores interlocutores de Gramsci no Brasil, que em seu trabalho docente foi responsável pela formação direta ou indireta de grande parte dos quadros intelectuais que contribuíram e contribuem com a análise da realidade tendo como ponto de partida Marx, Lucáks e Gramsci.

Conforme já sinalizava Netto, em 2012, a respeito da obra de Carlos Nelson, trata-se de uma obra em que a crítica literária, cultural e social dá as mãos à elaboração teórica e política e à intervenção sociocêntrica. Obra que, diferenciada no curso de sua constituição, tem o seu fundamento numa rigorosa e criativa exegese de Marx, Lukács e Gramsci e se desenvolve numa unidade garantida, entre outros componentes, pela sempre reafirmada opção revolucionária de Carlos Nelson. Obra que, como poucas produzidas por pensadores da sua geração, confere a ele um relevo notável entre todos os seus contemporâneos. ${ }^{9}$

Não poderíamos deixar de mencionar a professora Ivete Simionatto da UFSC, cuja contribuição para o Serviço Social na América Latina (e não só) tem um valor incomensurável. Não é por acaso que o nosso dossiê tem a honra de ter seu artigo na abertura.

Assim, abrindo o dossiê e este número, o artigo da professora Ivete Simionatto, da Universidade Federal de Santa Catarina, intitulado Gramsci de um século ao outro: sua presença no Serviço Social brasileiro, traz uma importante contribuição para o debate e adensamento do pensamento de Gramsci no Serviço Social. A autora nos mostra como as principais ideias do pensador italiano foram incorporadas no debate teórico da área, assim como nos estudos que realizam as mediações com as particularidades da ação profisssional. Conforme a autora destaca, a influência gramsciana no Serviço Social data de meados da década de 60 do século passado e se intensifica nos anos de 1980 e 1990, mas, para a autora, será a partir dos anos 2000 que esta influência se avoluma de fato, demostrando como alguns conceitos trabalhados por Gramsci retornam ao debate contemporâneo, dando destaque ao conceito de Estado integral e a sua mediação com as políticas sociais (sociedade política e sociedade civil). A questão da "guerra cultural" também é lembrada pela professora, mostrando como a cultura

${ }^{8}$ ibidem, p. 90.

${ }^{9}$ NETTO, J. P. Homenagem de vida ao Carlos Nelson Coutinho. In Revista em Pauta, 2012, p. 84. 
é essencial para combater o senso comum. Conforme nos lembra Simionatto à p. 15 deste volume, "Para Gramsci, é no terreno do senso comum que as classes subalternas incorporam as ideologias dominantes, cuja pretensa verdade se impõe como única, como superstição. E quando o Estado quer criar o consenso em torno de uma 'ação pouco popular' [...], cria preventivamente a opinião pública adequada, ou seja, organiza e centraliza certos elementos da sociedade civil” (GRAMSCI, CC, 2000, p. 265; Q, 1977, p. 914).

O segundo texto é de autoria dos professores Maria Lucia Duriguetto e Rodrigo de Souza Filho, ambos da Universidade Federal de Juiz de Fora, denominado Considerações sobre a questão da política no pensamento de Antônio Gramsci. Os autores, de reconhecida trajetória acadêmico-política, tematizam os fundamentos teórico-analíticos do tratamento da política em Gramsci, destacando algumas das categorias fundamentais para este autor, como Estado integral, hegemonia, práxis política entre outras. A tese central dos autores é que, para Gramsci, a política é "uma mediação insuprimível para a construção de processos que nos levam à superação da ordem do capital e à construção da "'sociedade regulada', nome que Gramsci usava para se referir ao comunismo" (cf. pg. 20, neste).

O terceiro texto, intitulado Gramsci sobre Vico: A filosofia como uma forma da política, de autoria do professor italiano Marco Vanzulli, que possui uma importante interlocução com o Brasil, tendo sido professor visitante em várias universidades e colaborador de destacadas revistas no nosso país, dentre elas a Crítica Marxista. É professor de Filosofia da Università degli Studi de Milano-Bicocca. O artigo traz importante e polêmica contribuição para o debate a respeito da política em Gramsci, com enfoque privilegiado para a "influência decisiva exercida pelas leituras de Benedetto Croce nas impressões de Gramsci sobre a obra de Giambattista Vico" (cf. 39, neste).

O quarto texto: Como estudar o Quaderno 25? Notas propositivas para uma metodologia de pesquisa sobre as classes e grupos subalternos em Antonio Gramsci, de Mirele Hashimoto Siqueira, traz um importante debate teórico problematizando os conceitos de classes e grupos subalternos na obra gramsciana, particularmente, do Quaderno 25. A autora mostra como o Caderno 25 é alvo de polêmicas, considerando a ampla recepção e apropriação do mesmo em âmbito internacional. A autora conclui que "Nessa perspectiva, para o Serviço Social brasileiro, estudar Gramsci e, particularmente, seus conceitos de classes e grupos subalternos, é fundamental para desvelar os mecanismos de dominação que forçam a reprodução deste estado no contexto das relações sociais atuais" (cf. p. 69, neste).

No quinto texto do Dossiê, Carta ao comunista Sardo, a professora Ana Lívia Adriano, apresenta, de forma original, um fecundo diálogo com Gramsci. Conforme a autora indica, 
trata-se de um texto "de natureza propedêutica ao estudo da obra gramsciana - é um esforço de síntese da apreensão das potencialidades e asperezas que peculiarizam os diálogos que construímos - enquanto sociedade e profissão - com o comunista sardo, os quais parecem conservar como fio de unidade, a conexão vital e necessária que a obra deste autor tem com os de baixo, na crítica radical e contumaz a este mundo terrível” (p. 71, neste). Trata-se de um texto que nos incita ao dialogo das categorias gramscianas com o Serviço Social, especialmente com as classes subalternas, com a hegemonia e a construção do projeto ético político.

Integrando o dossiê da presente edição, temos a homenagem realizada pela professora Cristina Simões Bezerra, a Carlos Nelson Coutinho, um dos mais destacados tradutores difusores da obra de Gramsci no Brasil. Denominado A atualidade de Gramsci no Brasil e a contribuição do pensamento de Carlos Nelson Coutinho, o texto relembra a trajetória do marxista brasileiro, refletindo ainda a respeito da atualidade da obra gramsciana para pensar os problemas do presente, assim como evidencia a contribuição de Carlos Nelson para, a partir das elaborações do marxista italiano, na interpretação da sociedade brasileira.

O texto de autoria das professoras Emilie Faedo Della Giustina e Danuta Estrufika Cantóia Luiz, intitulado $O$ debate do Estado e da sociedade civil em Gramsci e no Serviço Social, traz um debate bastante caro ao Serviço Social: as elaborações gramscianas a respeito da sociedade civil. As autoras afirmam que "Há, entre o pensamento gramsciano e as elaborações teórico-metodológicas e ético-políticas do Serviço Social uma íntima interlocução e, uma das principais temáticas dessa ligação se dá por meio de sua concepção de Estado e sociedade civil" (p. 97, neste).

Greice dos Reis Santos e Marina Valéria Delage Vicente Mancini, em Os intelectuais em Gramsci: uma análise sobre o papel dos/as assistentes sociais, apresentam um debate frutífero sobre o "intelectual" na perspectiva marxiana e especialmente na perspectiva gramsciana, questionando se o assistente social poderia ser pensado como um intelectual orgânico das classes expropriadas de seus direitos fundamentais. Como afirmam as autoras uma questão a ser debatida e aprofundada.

O ensaio de Maria José da Silva, denominado Os projetos em disputa do direito à saúde no Brasil: reflexões a partir de Gramsci, aborda os projetos em disputa na saúde pública e como os dois principais projetos de saúde no Brasil, o privatista e o da reforma sanitária, vem disputando a hegemonia. A autora conclui que é necessário defender a "construção de uma contra-hegemonia, conforme o pensamento gramsciano, ao projeto privatista na saúde, para assim fortalecermos o projeto da reforma sanitária dos anos 1980, que na realidade ainda caminha para conseguir fixar sua concepção de direito à saúde no país” (p. 147, neste). 
Encerra o Dossiê o artigo de Clara Barbosa de Oliveira Santos: A arte como ferramenta para a comunicação militante: um paralelo entre o projeto "Funkeiros Cult" e o pensamento gramsciano. A autora, tendo como base a perspectiva gramsciana, analisa o projeto "Funkeiros Cults", criado por estudantes e moradores da periferia. A autora busca demonstrar como o "projeto é uma iniciativa de demasiada importância para desmistificar a noção de 'intelectual' como algo elitizado e estritamente acadêmico, entendendo que o projeto 'Funkeiros Cults', bem como outros, devem estar atrelados a um projeto societário de superação da ordem do capital" (p. 149, neste).

$\mathrm{Na}$ sessão de artigos de fluxo continuo, apresentamos dois textos que, de forma diferenciada, analisam o território e as particularidades regionais no Brasil.

O primeiro, "O nosso lugar": embelezamento de cidades, memória e resistência das/os remanescentes do Projeto Portal da Amazônia/orla em Belém (PA), de autoria de Margareth Padinha das Chagas, da professora Joana Valente Santana e do professor Pedro Paulo de Miranda Araújo Soares, analisou o Projeto Portal da Amazônia em Belém do Pará. A pesquisa demostrou como o Projeto Orla "reforça a segregação socioespacial, agrava as condições de moradia e a insegurança da posse. A pesquisa revelou, ainda, como o lugar da memória, do vivido e do valor de uso contrapõe-se ao lugar da intervenção, do valor de troca e da cidade mercantilizada" (p. 160, neste).

No segundo, Crise urbana, desigualdades sociais e a pandemia do novo coronavírus no Brasil, Ivaneide Duarte de Freitas analisa a crise urbana no Brasil e os rebatimentos da pandemia sobre a classe trabalhadora. A autora conclui que "o advento e espraiamento do SarsCov-2 em terras brasileiras agudizam e aprofundam as desigualdades sociais já existentes em nosso território, tornando-se urgente a necessidade de organização política dos(as) trabalhadores(as) na luta pelo direito à vida e pela construção de uma nova ordem social" (p. 180, neste).

O terceiro artigo da sessão de fluxo contínuo, de autoria da professora Raquel Mota Mascarenhas, denominado A quimera do desenvolvimento sustentável para supressão da pobreza e da crise ecológica, analisa o modo de produção capitalista na cena contemporânea e a relação entre "pobreza e crise ecológica". Tendo como metodologia de análise "o método comparado e a pesquisa bibliográfica e documental, o trabalho apresenta considerações em três momentos: a relação entre crise ecológica e pobreza na contemporaneidade; o processo de construção da Agenda 2030 da ONU; desenvolvimento sustentável na América Latina, similitudes e particularidades em Brasil e Cuba" (p. 201, neste).

Segue-se o texto denominado de Tecnologias de vigilância na assistência social: o velho 
sob o manto do novo, de Gabriele Gomes de Faria, problematiza as novas tecnologias utilizadas no âmbito de assistência social. A autora mostra a retomada do conservadorismo nesta política, e as implicações para profissionais que nela se inserem, especialmente assistentes sociais. A autora questiona sobre a possibilidade destes profissionais serem chamados para “operacionalidade destes mecanismos que se avolumam num cenário de tendências regressivas em ações manipuladoras, fiscalizadoras que envolvem a profissão e que impactam escolhas e organizam a dominação por meio de estratégia passível de reproduzir uma conduta e um pensamento capazes de potencializar a vigia e a dominação" (p. 214, neste).

Em Mercado de trabalho no Brasil: particularidades da formação social e econômica e a universalidade sistêmica do capital, Mariana Costa Carvalho traz um estudo acerca da constituição do mercado de trabalho no Brasil, partindo da construção da formação sócio histórica do país, com destaque para o fim do regime escravista e a constituição da força de trabalho livre. A autora conclui que "Na fase atual, de financeirização e crise de realização do valor, as principais marcas do trabalho envolvem maior expressão de informalidade, precarização e flexibilização das relações. Somam-se os elementos estruturantes da formação social e econômica brasileira que aprofundam a superexploração do trabalho e recaem, mais fortemente, na população negra" (p. 236, neste).

O artigo de Vânia Ferreira de Assunção, Perfil socioeconômico da estudante do curso de serviço social da UFF - Rio das Ostras em 2019: desafios para a formação profissional em um campus precarizado, partindo de pesquisa quanti-qualitativa, traz uma análise sobre o perfil das estudantes do curso de Serviço Social da UFF-Rio das Ostras e "os dilemas da educação superior em um campus de estrutura precarizada e falta das condições necessárias de ensino/aprendizagem, expõem-se suas condições socioeconômicas e sua trajetória estudantil e a organização da sua vida acadêmica" (p. 256, neste).

Já em O caráter educativo na formação acadêmica dos/as assistentes sociais, Taciane Couto Gonçalves, tendo como base a pesquisa documental, analisou a presença do caráter educativo do Serviço Social na formação profissional. Para a autora, esta questão ainda aparece pouco explorada e evidenciada. Como conclui a autora: "tão importante quanto estar politicamente ao lado da classe trabalhadora, é colocar a serviço do seu projeto societário nosso saber técnico (ainda que a tarefa educativa vá muito além, difundir e democratizar o saber é também democratizar o poder) e vincular a prática educativa crítica às lutas sociais desenvolvidas pelo conjunto da classe trabalhadora" (p. 301, neste).

O texto denominado A perspectiva pedagógica do/a assistente social na superação do estigma em drogas, de Aline Cristina da Paixão Costa, possui como objetivo central trazer 
elementos que contribuam para refletir sobre o trabalho profissional do assistente social na superação aos estigmas em drogas, destacando a dimensão pedagógica que este profissional possui. O artigo tem como base a "análise crítica a respeito da atual conjuntura sofrida pela Política de Saúde Mental e na Atenção a álcool e outras drogas, levando em consideração diversos desafios para os/as assistentes sociais com relação aos estigmas” (p. 303, neste).

Finaliza esta sessão o texto de André Viana Custódio e Andréa Silva Albas Cassionato, A proteção de crianças e adolescentes contra castigos físicos aplicados por pais ou responsáveis. Por meio de pesquisa bibliográfica e documental, os autores buscaram "estudar as estratégias para o enfrentamento da violência intrafamiliar decorrente dos maus tratos contra crianças e adolescentes pela aplicação de castigos moderados através da contextualização desse tipo de violência a partir da aprovação da Lei Menino Bernardo em 2014, caracterizá-la juridicamente como maus tratos e analisar as diretrizes para enfrentá-la de tal maneira que possa ser identificado se as políticas públicas preveem ações para combate ao problema" (p. 324, neste). $\mathrm{O}$ artigo conclui apontando a existência de uma cultura da violência e a fragilidade das políticas públicas para o seu enfrentamento.

Finalmente, encerrando este número, na seção Entrevistas, complementando o Dossiê apresentado nesta edição, contamos com a importante colaboração das professoras Ivete Simionatto e Maria Lúcia Duriguetto, que entrevistaram o professor de história do pensamento político na Universidade da Calábria e atual presidente da International Gramsci Society Italia (IGS Italia), Guido Liguori. A entrevista traz uma importante contribuição para conhecer de forma mais aprofundada o pensamento de Gramsci. Liguori esclarece que, na escrita gramsciana, “A economia (...) não é negligenciada e a acusação de politicismo soa estranha. Em primeiro lugar porque Gramsci no Quaderni esclareceu, no entanto, que a hegemonia deve incidir na esfera política, social e cultural, mas em ligação indispensável à econômica, escrevendo entre outras coisas: 'se a hegemonia é ético-política, não pode deixar de ser também econômica, não pode deixar de ter o seu fundamento na função decisiva que o grupo dirigente exerce no núcleo decisivo da atividade econômica' (Q 13, § 18)” (p. 348, neste).

E na sessão Tradução dos Clássicos, como não poderia ser diferente, a prof. Cristina Simões Bezerra nos oferece a tradução de dois textos de Gramsci inéditos no Brasil, publicados em periódicos italianos: Filantropia, Boa vontade e Organização, de 1917 e Cultura e luta de classes, de 1918, ambos do período pré-carcerário, quando o marxista italiano polemizava vigorosamente, como jornalista.

Desejamos uma boa leitura! 